\title{
Ease and Difficulty in L2 Phonology: A Mini-Review
}

\author{
John Archibald* \\ Department of Linguistics, University of Victoria, Victoria, BC, Canada
}

A variety of phonological explanations have been proposed to account for why some sounds are harder to learn than others. In this mini-review, we review such theoretical constructs and models as markedness (including the markedness differential hypothesis) and frequency-based approaches (including Bayesian models). We also discuss experimental work designed to tease apart markedness versus frequency. Processing accounts are also given. In terms of phonological domains, we present examples of feature-based accounts of segmental phenomena which predict that the L1 features (not segments) will determine the ease and difficulty of acquisition. Models which look at the type of feature which needs to be acquired, and models which look at the functional load of a given feature are also presented. This leads to a presentation of the redeployment hypothesis which demonstrates how learners can take the building blocks available in the $\mathrm{L} 1$ and create new structures in the L2. A broader background is provided by discussing learnability approaches and the constructs of positive and negative evidence. This leads to the asymmetry hypothesis, and presentation of new work exploring the explanatory power

OPEN ACCESS

Edited by: Juhani Järvikivi,

University of Alberta, Canada

Reviewed by: Anne-Michelle Tessier, University of

British Columbia, Canada John H. G. Scott,

University of Calgary, Canada

${ }^{*}$ Correspondence: John Archibald johnarch@uvic.ca

Specialty section: This article was submitted to Language Sciences,

a section of the journal Frontiers in Communication

Received: 06 November 2020 Accepted: 14 January 2021 Published: 03 March 2021

Citation: Archibald J (2021) Ease and Difficulty in L2 Phonology: A Mini-Review. Front. Commun. 6:626529. doi: 10.3389/fcomm.2021.626529 of a contrastive hierarchy approach. The mini-review is designed to give readers a refresher course in phonological approaches to ease and difficulty in acquisition which will help to contextualize the papers presented in this collection.

Keywords: L2 phonology, L2 speech, second language acquisition (SLA), redeployment, learnability

\section{INTRODUCTION}

Why are some sounds harder to learn than others? A Japanese learner of English may have difficulty acquiring a novel L2 English [1]/[1] contrast (Brown, 2000) but less difficulty acquiring a novel L2 Russian $[1] /[\mathrm{r}]$ contrast (Larson Hall, 2004). The same Japanese speaker may have no difficulty acquiring the novel L2 contrasts $[\mathrm{b}] /[\mathrm{v}]$ or $[\mathrm{s}] /[\theta]$ (Matthews, 2000). A Brazilian Portuguese learner of English may have difficulty acquiring consonant clusters such as [sl], [sn] or [st] which are absent from the L1 (Cardoso, 2007), while a Persian learner of English who also lacks L1 [sl], [sn] and [st] may find them quite easy to acquire (Archibald and Yousefi, 2018). A Spanish learner of English may find it easier to acquire the [i]/[I] contrast (which is absent from the L1) when learning Scottish English than British English (Escudero, 2002). There are also examples of so-called directionality of difficulty effects (Eckman, 2004). For example, an English learner of German might find it easier to suppress a final voicing contrast than a German learner of English would find it to learn to make a new L2 final voicing contrast. These are the types of facts researchers need to explain (the explanandum). In this short paper, I will provide an overview of some of the proposed phonological accounts (the explanans) of such cases of ease or difficulty.

We begin by asking what it means to have acquired a sound. To probe such a question from a phonological perspective means that we must tackle the question of contrast. Phonemes are used to 
represent lexical contrasts. Such contrasts must also be implemented phonetically in both production and perception. Given that L2 production and perception may well be nonnativelike, this raises the interesting question for the L2 phonologist of determining whether the individual is 1) producing an inaccurate representation accurately, or 2) producing an accurate representation inaccurately. A case of 1) would be where an L2 learner might have the same representation for both $/ \mathrm{l} /$ and $/ \mathrm{r} /$ (i.e., not making a phonemic liquid contrast) and who also merged the production of [l] and [r]. A case of 2) would be where a learner might have a representational contrast for $/ \mathrm{b} /$ and $/ \mathrm{p} /$ (i.e., making a phonemic VOT contrast) but not implementing the contrast in a nativelike fashion. Methodologically, this reveals that researchers (and teachers) cannot rely on inaccurate production as a diagnostic of non-nativelike representation.

This leads us to a related question concerning production vs. perception. Much work in L2 speech proceeds on the assumption that accurate perception must (logically and developmentally) precede accurate production (Flege, 1995). Thus, much of the literature focusses on assessing whether the subjects can discriminate phonetic contrasts reliably, and represent phonological contrasts accurately. However, there are certain cases where learners may be accurate in either production (Goto, 1971) or lexical discrimination (Darcy et al., 2012) tasks and yet remain inaccurate on discrimination tasks. In both cases, it may be that metalinguistic knowledge plays an important role.

Ever since the Contrastive Analysis Hypothesis (Lado, 1957), linguists have tried to predict which aspects of $\mathrm{L} 2$ speech would be easy or difficult to learn. Since the 50s, both the representational models of phonology and the learning theories have become more sophisticated, and this has led to a consideration of multiple factors in exploring the construct of difficulty. Such approaches stand in marked contrast to the models of cross-language speech production (Flege, 1995) and cross-language speech perception (Best and Tyler, 2007) which primarily invoke acoustic and articulatory factors to explain difficulty in acquisition.

In the field of second language acquisition (SLA), there have been many factors explored to account for aspects of learner variation, including variation in nativelikeness of L2 speech. The following factors have been explored:

- L1 transfer (Trofimovich and Baker, 2006)

- amount of experience (Bohn and Flege, 1992)

- amount of L2 use (Guion et al., 2000)

- age of learning (Abrahamsson and Hyltenstam, 2009)

- orthography (Escudero and Wanrooi, 2010; Bassetti et al. 2015)

- frequency (Davidson, 2006)

- attention (Guion and Pederson, 2007)

- training (Wang et al., 2003)

It goes without saying that all of these factors do come in to play in accounting for learner behavior. What I will focus on in this mini-review are key representational issues which have informed phonological approaches to the construct of ease and difficulty.

\section{REPRESENTATIONAL APPROACHES}

This mini-review is focusing on representational models of phonology. There is a rich literature on output-based approaches (Tessier et al., 2013; Jesney, 2014) which tend to emphasize the computational system which generates the output form rather than emphasizing the form of the underlying (or input) representation.

\section{Markedness}

Some have looked to the notion of markedness (Parker, 2012) as an explanation by suggesting that unmarked structures are easier to acquire than marked ones (Carlisle, 1998). For example, it could be argued that 3-consonant onsets (e.g., [str]) were more difficult to acquire than 2-consonant onsets (e.g., [tr]) because they were more marked. Even within 2-consonant sequences work such as Broselow and Finer (1991), Eckman and Iverson (1993) demonstrate that principles such as Sonority Sequencing instantiate markedness with greater sonority distance between the adjacent segments being less marked (i.e., [pj] would be less marked than $[\mathrm{fl}]$ ). Such machinery is designed to account for the observation that not all structures which are absent from the L1 are equally difficult to acquire in the L2. The developmental path would be from unmarked to marked structures.

Some have suggested that a markedness continuum was not enough but rather that markedness differential was the locus of explanation (Eckman, 1985). Under this approach, a structure which was absent from the L1 and more marked than the L1 structure would be difficult to acquire while one which was absent from the L1 but less marked than the L1 structure would be easier to acquire.

Often, however, the unmarked forms are the most frequent (e.g. 3-consonant clusters are more marked than 2-consonant clusters, and 3-consonant clusters are also less frequent than 2consonant clusters) so it is difficult to tease these factors apart. If learners are more accurate on 2-consonant clusters is it because they are more frequent or less marked?

\section{Frequency-Based Approaches}

Usage-based (Wulff and Ellis, 2018) and Bayesian (Wilson and Davidson, 2009) approaches argue that targetlike production accuracy is correlated with input frequency. Thus, if there are two elements which are absent from the $\mathrm{L} 1$ and one is frequent in the L2 input while one is infrequent, then the frequent structure might be more easily acquired.

\section{Frequency Versus Markedness}

Cardoso (2007) documents a scenario in which the most frequent structure is the most marked so we can tell which construct is most explanatory. In looking at the acquisition of L2 English consonant clusters by L1 speakers of Brazilian Portuguese, he focused on [st], [sn] and [sl]. Without getting into the details of the markedness facts here, [st] is both the most frequent and the 
most marked of the clusters. When it came to learner production, the learners were least accurate on the most marked cluster ([st]) even though it was most frequent in their input. For production (though not perception), markedness seemed to be more explanatory than frequency.

The construct of markedness itself has its critics (Haspelmath, 2006; Zerbian, 2015). If the notion is ill-defined measure of complexity-difficulty or abnormality? - then how can it be a valid explanans? Responding to Archibald (1998) who suggested that positing markedness as an explanation (rather than a description) only bumped the explanation problem back a generation (because what explains markedness?), Eckman (2008; 105) counter-argues that, "to reject a hypothesis because it pushes the problem of explanation back one step misses the point that all hypotheses push the problem of explanation back one step-indeed, such 'pushing back' is necessary if one is to proceed to higher level explanations."

\section{Processing Accounts}

While more work has been done on the role of the processor in morpho-syntax in SLA (O'Grady, 1996; O'Grady, 2006; Truscott and Sharwood Smith, 2004), Carroll (2001) explores the role of the phonological parser in mapping the acoustic signal onto phonological representations. Carroll (2013) addresses these questions in initial-state L2 learners empirically. There has also been some work done on L2 phonological parsing at the level of the syllable (Archibald, 2003; Archibald, 2004; Archibald, 2017) which suggests that structures which can be parsed are easier to acquire than structures which the parser cannot yet handle.

Such models intersect with the perception literature insofar as the L2 acoustic input is filtered by the L1 phonological system (Pallier et al., 2001). In turn, such perceptual shoe-horning can lead to activation of phantom lexical competitors (Broersma and Cutler, 2007) which may slow lexical activation.

The notion that only some input can be processed at any given time, thus leading to the intake to the processor being a subset of the environment input, is well-studied in applied linguistics (Corder, 1967; Schmidt, 1990). What has proved more elusive is explaining when input becomes intake (and when it does not). Certainly one of the challenges is avoiding circularity of the following sort:

Q: why is $\mathrm{x}$ produced/perceived accurately before $\mathrm{y}$ ?

A: Because it became intake

Q: How do you know it became intake?

A: Because it was produced/perceived accurately.

Processing accounts are not necessarily independent of abstract phonological studies as they have also been important in documenting the viability of abstract phonological features (Lahiri and Reetz, 2010; Schluter et al., 2017). Features can be explanatory when we note classes of sounds behaving in a similar fashion, for example, only nasals being allowed in syllable codas in a given L1. Thus difficulty may arise when these learners attempt to parse L2 stops into a coda. Note that the difficulty would affect, say, [p t k] as a class of voiceless stops.

\section{Representational Accounts}

Theories of phonological representation help us to model both synchronic and diachronic aspects of L2 phonological grammars. Özçelik (2016) addresses the general question of developmental path in L2 grammars (a fundamental concern of the field as we try to develop a transition theory). He proposes a cue-based model which clarifies which structural properties (i.e., parameters) are logical precursors to the acquisition of subsequent parameters. Özçelik and Sprouse (2016) demonstrate that interlanguage grammars are constrained by phonological universals (such as the behavior of feature spreading).

Feature-based models (Brown, 2000) can be contrasted with segment-based models (Flege, 1995). A segment-based model might say that a new segment will be difficult to acquire based on a comparison of the L1 and L2 phonetic categories. A featurelevel account would argue that new L2 contrasts which were based on distinctive features that were absent from the L1 would be difficult while new contrasts based on L1 features would be easy. Brown (2000) showed that Korean learners of English could acquire new contrasts if the contrasts were based on an existing L1 feature (e.g., [continuant]) while L2 contrasts which were not based on L1 features (e.g., [distributed]) were more difficult to acquire.

LaCharité and Prévost (1999) suggest that this was too strong an approach and that some features which were absent (i.e., terminal nodes) would be acquirable while others (i.e., articulator nodes) would not, as shown in (1). $\mathrm{h}$

[consonantal]
Place
PHARYNGEAL $\theta$

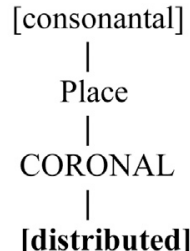

The features in boldface are the ones which are absent from the L1 French inventory. They predict that the acquisition of L2 English [h] will be more difficult than the acquisition of [ $\theta$ ] because [h] requires the learner to trigger a new articulator node. On a discrimination task, the learners were significantly less accurate identifying $[\mathrm{h}]$ than identifying $[\theta]$, however, on a word identification task (involving lexical access) there was no significant difference between the performance on [h] vs. $[\theta]$. Özçelik and Sprouse (2016), however, show that L2 learners are able to acquire the features of secondary articulations (e.g., palatalized consonants). Hancin-Bhatt (1994) proposed that the functional load of a particular feature in implementing a contrast in a language would determine its weighting (with features with high functional load predicted to have greater cross-linguistic influence than those with low functional load).

Archibald (2005) proposed the Redeployment Hypothesis in which it would be easier to acquire new L2 structures which could be built from existing L1 building blocks (e.g., features, or moras) than to acquire new building blocks. In some ways, this approach presages Lardiere's (2009) Feature Reassembly Hypothesis which 
looks to account for the difficulty that L2 learners have acquiring L2 morphology.

One example of redeployment is evidenced in the L2 acquisition of Japanese geminate consonants by L1 English speakers. Japanese geminate consonants have the moraic structure shown in (2).

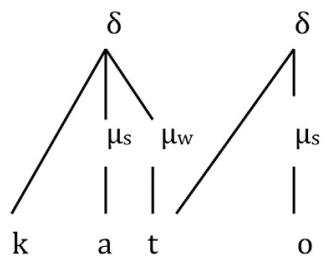

English does not have geminate consonants, but does have a weight-sensitive stress system, shown in (3) where coda consonants project moras which attracts stress to heavy syllables.

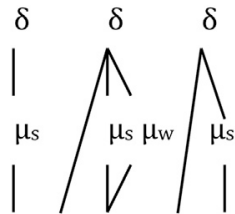

ə $\mathrm{r}$ ó $\mathrm{m}$ ə

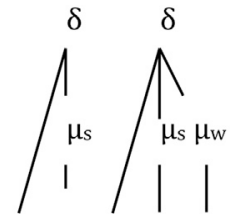

s $\quad \mathrm{I} \quad \mathrm{n} \quad \mathrm{a} \quad \mathrm{p}$

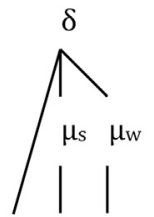

$\mathrm{S}$ ว $\mathrm{S}$
Thus, the English quantity-sensitive system can be redeployed to acquire L2 geminates. The corollary to this would be that L2 structures which could not be built from L1 components would be more difficult to acquire.

Cabrelli et al. (2019), looking at Brazilian Portuguese learners of English coda consonants, also demonstrate that L2 learners can restructure their phonological grammars insofar as the L2 learners are licensing coda consonants which are not found in the L1. Carlson (2018) found similar effects in L1 Spanish.

Garcia (2020) describes an interesting case where a property of the L2 (stress placement) which could be acquired on the basis of transferring an L1 property of weight-sensitivity is, in fact, difficult to acquire because another property of the L1 is able to account for the L2 data, and this property (positional bias) is more robust in the $\mathrm{L} 2$ input.

\section{Production, Perception and Representation}

Darcy et al. (2012) present data which show, contra Flege (1995), that some learners who were able to lexically represent a contrast were unable to accurately discriminate it. The model is known as DMAP which stands for direct mapping of acoustics to phonology. The basic empirical finding which they report on is a profile where L2 learners of French (with L1 English which lacks/y/) can distinguish lexical items which rely on a /y/ - /u/ distinction while simultaneously being unreliable in discriminating $[y]$ from $[u]$ in an ABX task. Detection of acoustic properties can lead to phonological restructuring (according to general economy principles of phonological inventories) which will result in a lexical contrast but the phonetic categories may not yet be targetlike. The learners rely on their current interlanguage

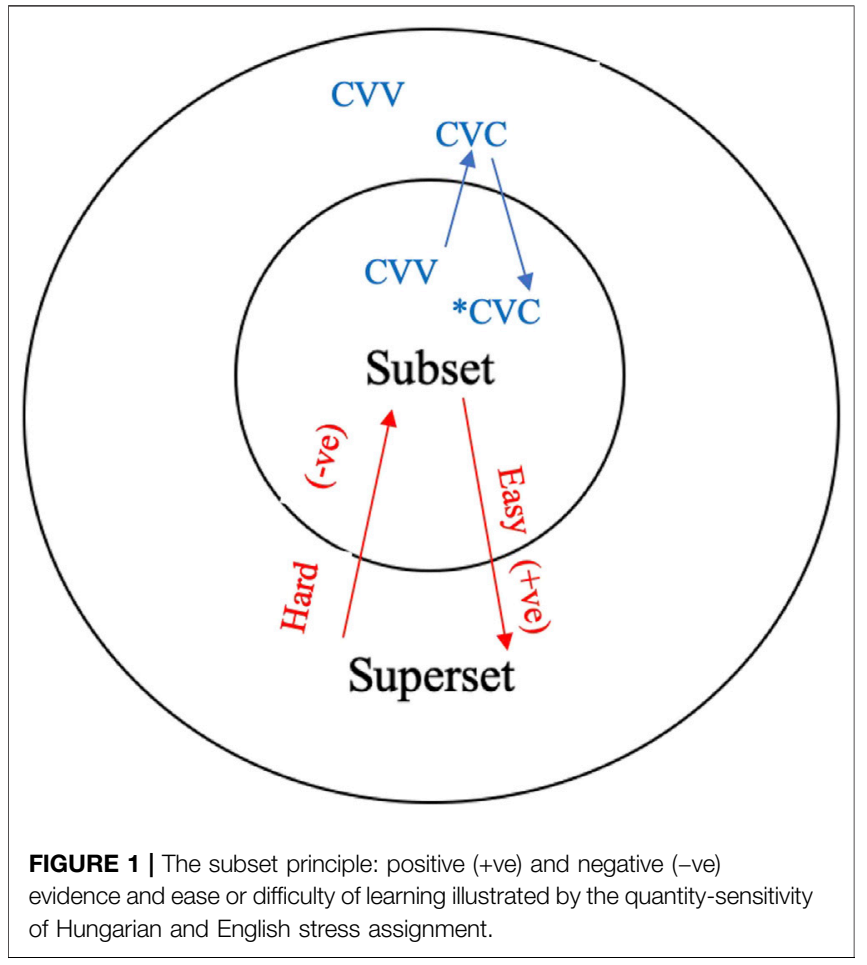

feature hierarchy to set up contrastive lexical representations even as phonetic category formation proceeds.

This is reminiscent of the Goto (1971) study where Japanese learners were able to produce an / //-/r/ liquid contrast even while not being able to discriminate between them in a decontextualized task. It could be that the tactile feedback received in the production of these two sounds, and the orthographic distinction between " $\mathrm{l}$ " and " $\mathrm{r}$ " were able to cue the learners' production systems. This sort of metalinguistic knowledge can affect production.

Davidson and Wilson (2016) extend a body of research which documents L2 learners' sensitivity to non-contrastive phonetic properties (which might account for occurrences of prothesis vs. epenthesis in cluster repair) to look at learner behavior in the classroom. While subjects listening in a classroom (compared to a sound booth) showed some differences (e.g., less prothesis repair), by and large the performance was very similar. This suggests that laboratory research may well have quite direct implications for classroom learners.

\section{Learnability and L2 Phonology}

Learnability approaches (Wexler and Culicover, 1980; Pinker, 1989; White, 1991) argued that learning would be faster when there was positive evidence that the L1 grammar had to change, while change that was cued only by negative evidence would be acquired more slowly. Positive evidence is evidence in the linguistic environment of well-formed structures. Negative evidence is evidence given to the learner that a particular string is ungrammatical. It would be easier to move from an L1 which was a subset of the L2 (because there is positive evidence to indicate that the current grammar is incorrect) than it would be 
to move from an L1 which was a superset of the L2 (as this would require negative evidence).

Consider the example of L1 English and L2 Hungarian as shown in Figure 1. Hungarian secondary stress (Kerek, 1971) is quantity-sensitive to the Nucleus (meaning that only branching nucleii (i.e., long vowels $(\mathrm{CVV})$ ) are treated as Heavy but not branching Rhymes (i.e., closed syllables (CVC)). English stress is quantity sensitive to branching nuclei and branching rhymes.

If your L1treated long (i.e., bimoraic) vowels (CVV) and closed syllables (CVC) as heavy (as English does) but the L2 only treated long vowels as heavy then it might take a while for the learner to hypothesize "wait, I've never heard a secondary stress on a closed syllable!”. But L1 Hungarian to L2 English would have clear positive evidence when the learner hears stress placed on a closed syllable (as in agénda). An English learner of Hungarian would have to notice that Hungarian never stressed closed syllables. Dresher and Kaye (1991) argued that when the data reveal that closed syllables and branching nuclei behave the same with respect to stress assignment this is the universal cue for the system to be quantity sensitive to the rhyme. See Archibald (1991) for further discussion and empirical investigation.

Young-Scholten's (1994, 2004) Asymmetry Hypothesis predicts that if an L2 phonological rule applies in a prosodic domain that is a superset of the L1 phonological domain then the positive evidence will make it easier to acquire. However, when the target domain is smaller than the L1 domain then the lack of positive evidence will make acquisition more difficult. In English, the rule of flapping applies within a phonological utterance (e.g., Don't sit on the mat [r], it's dirty.). German has a rule of final devoicing which applies within a phonological word (e.g., Ich ha $[\mathrm{b}] e \sim \operatorname{Ich} h a b[\mathrm{p}])$. So, English learners of German are predicted to have difficulty acquiring phonological patterns which are licensed only in smaller phonological domains.

In addition to positive evidence or direct negative (i.e., correction) evidence, however, Schwartz and Goad (2017) have demonstrated that indirect positive evidence can play a role in second language learning where the L2 is a subset of the L1. In

\section{REFERENCES}

Abrahamsson, N., and Hyltenstam, K. (2009). Age of onset and nativelikeness in a second language: listener perception versus linguistic scrutiny. Lang. Learn. 59 (2), 249-306. doi:10.1111/j.1467-9922.2009.00507.x

Archibald, J. (1991). Language learnability and L2 phonology: the acquisition of metrical parameters. Dordrecht: Kluwer.

Archibald, J. (2004). Interfaces in the prosodic hierarchy: new structures and the phonological parser. Int. J. Bilingualism 8 (1), 29-50. doi:10.1177/ 13670069040080010301

Archibald, J. (2003). Learning to parse second language consonant clusters. Can. J. Linguistics 48 (3/4), 149-177. doi:10.1353/cjl.2004.0023

Archibald, J. (1998). Second Language Phonology. Amsterdam, NL: John Benjamins.

Archibald, J. (2005). Second language phonology as redeployment of L1 phonological knowledge. Can. J. Linguistics 50 (1/2/3/4), 285-314. doi:10. 1353/cjl.2007.0000

Archibald, J. (2017). "Transfer, contrastive analysis and interlanguage phonology," in The Routledge handbook of English pronunciation. Editors R. Thompson, O. Kang, and J. Murphy (London, UK:Routledge), 9-24. this case, L2-accented English was shown to be a source of evidence for some subjects as to the phonotactics of Brazilian Portuguese.

There is one area which is just starting to be explored in L2 phonology and that is Dresher (2009) contrastive hierarchy as an explanatory tool for ease and difficulty. Dresher's model suggests that L2 features which are active (i.e., involved in many phonological processes in the language) will be easier to learn than L2 features which are inactive due to the type of evidence they present to the learner. Active features provide robust cues to the learner that a given feature must be highly ranked in a contrastive hierarchy, and is, therefore, evidence to restructure the L1 hierarchy. Archibald (2020) has explored this model in an analysis of L3 phonological systems. Such a mechanism is reminiscent of Hancin-Bhatt (1994) notion of how functional load defines featural prominence.

\section{CONCLUSION}

What I have attempted to show in this mini-review is that there is a rich history in addressing the question of ease vs. difficulty in L2 phonology. I hope that this overview will provide useful background to the readers of this collection. Unsurprisingly, there is no easy answer to the difficult question of ease vs. difficulty.

\section{AUTHOR CONTRIBUTION}

I am the sole author of this piece.

\section{ACKNOWLEDGMENTS}

I would like to thank the reviewers for this piece. Their keen eye for clarity and accuracy has greatly improved this mini-review. But I have to say that the friendly, supportive scholarly exchange was as enjoyable as it is rare.

Archibald, J. (2020). in Microvariation in multilingual situations: the importance of property-by-property acquisition. Turtles all the way down: micro-cues and piecemeal transfer in L3 phonology. Commentary on Westergaard. Second Language Research. doi:10.1177/0267658320941036

Archibald, J., and Yousefi, M. (2018). "The redeployment of marked L1 Persian codas in the acquisition of marked L2 English onsets: redeployment as a transition theory," in Paper presented at conference on central Asian language and linguistics, Bloomington, IN, April 17-April 19, 2020 (Bloomington, IN: Indiana University).

Bassetti, B., Escudero, P., and Hayes-Harb, R. (2015). Second language phonology at the interface between acoustic and orthographic input. Appl. Psycholinguistics 36, 1-6. doi:10.1017/s0142716414000393

Best, C., and Tyler, M. D. (2007). "Nonnative and second-language speech perception: commonalities and complementarities," in Second language speech learning: the role of language experience in speech perception and production. Editors M. J. Munro and O.-S. Bohn (Amsterdam, NL: John Benjamins Publishing), 13-34.

Bohn, O. S., and Flege, J. E. (1992). The production of new and similar vowels by adult German learners of English. Stud. Second Lang. Acquisition 14 (2), 131-158. doi:10.1017/s0272263100010792 
Broersma, M., and Cutler, A. (2007). Phantom word activation in L2. System 36, 22-34. doi:10.1016/j.system.2007.11.003

Broselow, E., and Finer, D. (1991). Parameter setting in second language phonology and syntax. Second Lang. Res. 7 (1), 35-59. doi:10.1177/ 026765839100700102

Brown, C. (2000). "The interrelation between speech perception and phonological acquisition from infant to adult," in Second language acquisition and linguistic theory. Editor J. Archibald (Hoboken, NJ: Wiley-Blackwell), 4-63.

Cabrelli, J., Luque, A., and Finestrat-Martinez, I. (2019). Influence of L2 English phonotactics in L1 Brazilian Portuguese illusory vowel perception. J. Phonetics 73, 55-69. doi:10.1016/j.wocn.2018.10.006

Cardoso, W. (2007). "The development of $\mathrm{sC}$ onset clusters in interlanguage: markedness vs. frequency effects," in Proceedings of the 9th generative approaches to second language acquisition conference (GASLA 2007), May 18-20, 2007. Editors R. Slabakova, J. Rothman, P. Kempchinsky, and E. Gavruseva (Cascadilla Press), 15-29.

Carlisle, R. S. (1998). The acquisition of onsets in a markedness relationship: a longitudinal study. Studies in second language acquisition 20, 254-260. doi:10. 1017/S027226319800206X

Carlson, M. T. (2018). Making room for second language phonotactics: effects of L2 learning and environment on first language speech perception. Lang. Speech 61, 598-614. doi:10.1177/0023830918767208

Carroll, S. (2001). Input and evidence: the raw material of Second Language acquisition. Amsterdam, NL: John Benjamins Publishing

Carroll, S. (2013). Introduction to the special issue: aspects of word learning on first exposure to a second language. Second Lang. Res. 29 (2), 131-144. doi:10.1177/ 0267658312463375

Corder, S. P. (1967). The significance of learners' errors. Int. Rev. Appl. Linguistics 5, 160-170. doi:10.1515/iral.1967.5.1-4.161

Darcy, I., Dekydtspotter, L., Sprouse, R., Glover, J., Kaden, C., McGuire, M., and Scott, J. (2012). Direct mapping of acoustics to phonology: on the lexical encoding of front rounded vowels in L1 English-L2 French acquisition. Second Lang. Res. 28 (1), 5-40. doi:10.1177/0267658311423455

Davidson, L. (2006). Phonology, phonetics, or frequency: influences on the production of non-native sequences. J. Phonetics 34, 104-137. doi:10.1016/j. wocn.2005.03.004

Davidson, L., and Wilson, C. (2016). Processing nonnative consonant clusters in the classroom: perception and production of phonetic detail. Second Lang. Res. 32 (4), 471-501. doi:10.1177/0267658316637899

Dresher, B. E., and Kaye, J. (1991). A computational learning model for metrical phonology. Cognition 34, 137-195.

Dresher, E. B. (2009). The contrastive hierarchy in phonology. Cambridge, UK: Cambridge University Press.

Eckman, F. (2004). From phonemic differences to constraint rankings. SSLA 26 (4), 513-549. doi:10.1017/s027226310404001x

Eckman, F., and Iverson, G. (1993). Sonority and markedness among onset clusters in the interlanguage of ESL learners. Second Lang. Res. 9, 234-252. doi:10.1177/ 026765839300900302

Eckman, F. (1985). Some theoretical and pedagogical implications of the markedness differential hypothesis. Stud. Second Lang. Acquisition 7, 289-307. doi:10.1017/S0272263100005544

Eckman, F. (2008). "Typological markedness and second language phonology," in Phonology and second language acquisition. Editors J. Hansen and M. Zampini (Amsterdam, NL: John Benjamins Publishing), 95-115.

Escudero, P. (2002). "The perception of English vowel contrasts: acoustic cue reliance in the development of new contrasts," in Proceedings of the 4th International Symposium on the Acquisition of Second-Language Speech, New Sounds, September, 2000.

Escudero, P., and Wanrooij, K. (2010). The effect of L1 orthography on non-native vowel perception. Lang. Speech 53 (3), 343-365. doi:10.1177/0023830910371447

Flege, J. E. (1995). "Second language speech learning: theory and findings and problems," in Speech perception and linguistic experience: issues in crosslinguistic research. Editor W. Strange (York, UK: York Press), 233-277.

Garcia, G. D. (2020). Language transfer and positional bias in English stress. Second Lang. Res. 36 (4), 445-474. doi:10.1177/0267658319882457

Goto, H. (1971). Auditory perception by normal Japanese adults of the sounds "L" and "R". Neuropsychologia 9, 317-323. doi:10.1016/0028-3932(71)90027-3
Guion, S., Flege, J. E., Liu, S., and Yeni-Komshian, G. (2000). Age of learning effects on the duration of sentences produced in a second language. Appl. Psycholinguistics 21, 205-228. doi:10.1017/s0142716400002034

Guion, S., and Pederson, E. (2007). "Investigating the role of attention in phonetic learning," in Second language speech learning: the role of language experience in speech perception and production. Editors O.-S. Bohn and M. Munro (Amsterdam, NL: John Benjamins Publishing), 99-116.

Hancin-Bhatt, B. (1994). Segment transfer: a consequence of a dynamic system. Second Lang. Res. 10 (3), 241-269. doi:10.1177/026765839401000304

Haspelmath, M. (2006). Against markedness (and what to replace it with). J. Linguistics 42, 25-70. doi:10.1017/s0022226705003683

Jesney, K. (2014). "A learning-based account of L1 vs. L2 cluster repair differences," in Selected Proceedings of the 5th Conference on generative Approaches to language acquisition north America (GALANA 2012), University of Kansas, October 11-13, 2012. Editors C. Y. Chu, C. E. Coughlin, B. L. Prego, U. Minai, and A. Tremblay (Somerville, MA: Cascadilla Proceedings Project), 10-21.

Kerek, A. (1971). Hungarian metrics. Bloomington, IN: Indiana University.

LaCharité, D., and Prévost, P. (1999). "The role of L1 and of teaching in the acquisition of English sounds by Francophones," in Proceedings of BUCLD 23. Editors A. Greenhill, H. Littlefield, and C. Tano (Somerville, MA: Cascadilla Press), 373-385.

Lado, R. (1957). Linguistics across cultures. Ann Arbor, MI: Michigan University Press.

Lahiri, A., and Reetz, H. (2010). Distinctive features: phonological underspecification in representation and processing. J. Phonetics 38, 44-59. doi:10.1016/j.wocn.2010.01.002

Lardiere, D. (2009). Some thoughts on the contrastive analysis of features in second language acquisition. Second Lang. Res. 25 (2), 173-227. doi:10.1177/ 0267658308100283

Larson-Hall, J. (2004). Predicting perceptual success with segments: a test of Japanese speakers of Russian. Second Lang. Res. 20 (1), 33-76. doi:10.1191/ 0267658304sr230oa

Matthews, J. (2000). "The influence of pronunciation training on the perception of second language contrasts," in New sounds 1999. Editors J. Leather and A. James (University of Klagenfurt Press), 223-229.

Özçelik, Ö., and Sprouse, R. (2016). Emergent knowledge of a universal phonological principle in the L2 acquisition of vowel harmony in Turkish: a "four"-fold poverty of the stimulus in L2 acquisition. Second Lang. Res. 33 (2), 179-206. doi:10.1177/0267658316679226

Özçelik, Ö. (2016). The prosodic acquisition path hypothesis: towards explaining variability in L2 acquisition of phonology. Glossa 1 (1), 1-48. doi:10.5334/ggl.47

O'Grady, W. (1996). Language acquisition without Universal Grammar: a general nativist proposal for L2 learning. Second Lang. Res. 12 (4), 364-397. doi:10. $1177 / 026765839601200403$

O'Grady, W. (2006). "The syntax of quantification in SLA: an emergentist approach," in Proceedings of the 8th generative Approaches to second language acquisition conference (GASLA 2006): the Banff conference, Banff, Canada, April 27-30, 2006. Editors M. O'Brien, C. Shea, and J. Archibald (Somerville, MA: Cascadilla Press), 98-113.

Pallier, C., Colomé, A., and Sebastián-Gallés, N. (2001). The influence of nativelanguage phonology on lexical access: exemplar-based versus abstract lexical entries. Psychol. Sci. 12, 445-449. doi:10.1111/1467-9280.00383

Parker, S. (2012). "Sonority distance vs. sonority dispersion - a typological survey," in The sonority controversy. Editors S. Parker and A. Lahiri (Berlin, Germany: De Gruyter Mouton), 101-166.

Pinker, S. (1989). Language learnability and cognition: the acquisition of argument structure. Cambridge, MA: MIT Press.

Schluter, K., Politzer-Ahles, S., Al Kaabi, M., and Almeida, D. (2017). Laryngeal features are phonetically abstract: mismatch negativity evidence from Arabic, English, and Russian. Front. Psychol. 8, 746. doi:10.3389/fpsyg.2017.00746

Schmidt, R. (1990). The role of consciousness in second language learning. Appl. Linguistics 11, 129-158. doi:10.1093/applin/11.2.129

Schwartz, M., and Goad, H. (2017). Indirect positive evidence in the acquisition of a subset grammar. Lang. Acquisition 24 (3), 234-264. doi:10.1080/10489223.2016.1187616

Tessier, A. M., Sorenson Duncan, T., and Paradis, J. (2013). Developmental trends and L1 effects in early L2 learners onset cluster production. Bilingualism: Lang. Cogn. 16 (3). doi:10.1017/s136672891200048x 
Trofimovich, P., and Baker, W. (2006). Learning second language suprasegmentals: effect of L2 experience on prosody and fluency characteristics of L2 speech. Stud. Second Lang. Acquisition 28 (1), 1-30. doi:10.1017/s0272263106060013

Truscott, J., and Sharwood Smith, M. (2004). Acquisition by processing: a modular perspective on language development. Bilingualism: Lang. Cogn. 7 (1), 1-20. doi:10.1017/s1366728904001178

Wang, Y., Jongman, A., and Sereno, J. (2003). Acoustic and perceptual evaluation of Mandarin tone productions before and after perceptual training. J. Acoust. Soc. Am. 113, 1033. doi:10.1121/1.1531176

Wexler, K., and Culicover, P. (1980). Formal principles of language acquisition. Cambridge, MA: MIT Press.

White, L. (1991). Adverb placement in second language acquisition: some effects of positive and negative evidence in the classroom. Second Lang. Res. 7, 133-161. doi:10.1177/026765839100700205

Wilson, C., and Davidson, L. (2009). Bayesian analysis of non-native cluster production. Proc. NELS 40.

Wulff, S., and Ellis, C. N. (2018). "Usage-based approaches to second language acquisition," in Bilingual cognition and language: the state of the science across its subfields. Editors D. T. Miller, F. Bayram, J. Rothman, and L. Serratrice (Amsterdam, NL: John Benjamins Publishing), 37-56.
Young-Scholten, M. (1994). On positive evidence and ultimate attainment in L2 phonology. Second Lang. Res. 10, 193-214. doi:10.1177/ 026765839401000302

Young-Scholten, M. (2004). Prosodic constraints on allophonic distribution in adult L2 acquisition. Int. J. Bilingualism 8 (1), 67-77. doi:10.1177/ 13670069040080010501

Zerbian, S. (2015). "Markedness considerations in L2 prosodic focus and givenness marking," in Prosody and language in contact: L2 acquisition, attrition and languages in multilingual situations. Editors E. Delais-Roussarie, M. Avanzi, and S. Herment (Berlin, Germany: Springer), 7-27.

Conflict of Interest: The authors declare that the research was conducted in the absence of any commercial or financial relationships that could be construed as a potential conflict of interest.

Copyright (c) 2021 Archibald. This is an open-access article distributed under the terms of the Creative Commons Attribution License (CC BY). The use, distribution or reproduction in other forums is permitted, provided the original author(s) and the copyright owner(s) are credited and that the original publication in this journal is cited, in accordance with accepted academic practice. No use, distribution or reproduction is permitted which does not comply with these terms. 